DOI: https://doi.org/10.24867/07BE02Pavlovic

\title{
UTICAJ STRUJNIH MERENJA NA PRORAČUN STATIČKE ESTIMACIJE STANJA U PRENOSNIM MREŽAMA
}

\section{INFLUENCE OF CURRENT MEASUREMENTS ON STATIC STATE ESTIMATION CALCULATION IN ELECTRIC POWER SYSTEMS}

\author{
Miroslav Pavlović, Fakultet tehničkih nauka, Novi Sad
}

\begin{abstract}
Oblast - ELEKTROTEHNIKA I RAČUNARSTVO
Kratak sadržaj - U ovom radu razmatrana je statička estimacija stanja, kao bazična funkcija za većinu proračuna vezanih za analizu, eksploataciju i upravljanje elektroenergetskim sistemima. Posebna pažnja posvećena je korišćenju strujnih merenja u proračunu statičke estimacije. Predstavljen je matematički model korišćen za proračun statičke estimacije stanja u prisustvu strujnih merenja i izvršena verifikacija modela na test sistemima sa 3 i 14 čvorova.
\end{abstract}

Ključne reči: Statička estimacija stanja, observabilnost sistema, strujna merenja.

\begin{abstract}
In this paper, the static state estimation is considered, as a basic function for most of the calculations related to the analysis, exploitation and management of the electric power system. Special attention is paid to the use of current measurements in the static state estimation calculation. Mathematical model used for static state estimation calculation, in a presence of current measurements, is introduced and model verification is performed on 3 and 14-bus test systems.
\end{abstract}

Keywords: Static state estimation, system observability, current measurements.

\section{UVOD}

Statička estimacija stanja predstavlja bazičnu funkciju za većinu proračuna vezanih za analizu, eksploataciju i upravljanje elektroenergetskim sistemima (EES).

Kompletan proces statičke estimacije stanja odvija se kroz 6 koraka [1]: Formiranje modela, analiza observabilnosti sistema, statička estimacija stanja, detekcija i identifikacija loših merenja i estimacija parametara modela mreže.

Cilj ovog rada jeste da se da teorijska postavka prva 3 koraka statičke estimacije stanja.

Posebna pažnja biće posvećena strujnim merenjima koja su danas široko rasprostranjena u svim EES-ima. Biće objašnjene prednosti, kao i nedostaci korišćenja strujnih merenja u proračunu statičke estimacije stanja, odnosno metodu minimuma sume otežanih kvadrata reziduala.

\section{NAPOMENA:}

Ovaj rad proistekao je iz master rada čiji mentor je bio dr Goran Švenda, red. prof.
Rad će pored jasne postavke problema ponuditi i predloge za rešavanje istih, u skladu sa rezultatima algoritma implementiranog u programskim jezicima $\mathrm{C}++\mathrm{i}$ Fortran. U okviru primera, na test sistemima, biće izvršena analiza osetljivosti estimiranih vrednosti napona na grešku merenja modula struje u grani, kao i osetljivost estimiranih vrednosti na promenu izmerene vrednosti modula napona u čvorovima mreže.

\section{POSTAVKA PROBLEMA}

Osnovni pojmovi potrebni za razumevanje algoritma statičke estimacije stanja su: vektor stanja $\boldsymbol{x}$, vektor merenja $z$, varijansa $\sigma_{m}^{2}$, težinski faktor $w_{m}$ i redundansa merenja $R_{d}$.

Vektor stanja predstavlja n-dimenzioni vektor promenljivih stanja $\boldsymbol{x}$, izraz (1).

$$
\boldsymbol{x}=\left[\begin{array}{llll}
\boldsymbol{V} & \boldsymbol{\theta} & \boldsymbol{a}_{\boldsymbol{l}} & \boldsymbol{\varphi}_{\boldsymbol{l}}
\end{array}\right]^{T},
$$

gde je $\boldsymbol{V}$ vektor modula fazora napona, $\boldsymbol{\theta}$ vektor uglova fazora napona u svim čvorovima (osim referentnog balansnog), a $\boldsymbol{a}_{\boldsymbol{l}}$ i $\boldsymbol{\varphi}_{\boldsymbol{l}}$ vektori nenominalnih odnosa transformacije klasičnih i faznih regulacionih transformatora, respektivno.

Vektor merenja $z$ povezan je sa vektorom promenljivih stanja $\boldsymbol{x}$ preko nelinearne jednačine:

$$
\boldsymbol{z}=\boldsymbol{h}(\boldsymbol{x})+\boldsymbol{e},
$$

gde je $\boldsymbol{z} M$-dimenzioni vektor merenja, $\boldsymbol{h}(\boldsymbol{x}) M$-dimenzioni vektor funkcija promenljivih stanja, $\boldsymbol{x} n$-dimenzioni vektor promenljivih stanja i $\boldsymbol{e} M$-dimenzioni slučajni vektor grešaka merenja.

Vektor merenja koji se koristi u statičkoj estimaciji stanja se može predstaviti na sledeći način (preko 9 subvektora):

$$
\boldsymbol{z}=\left[\begin{array}{lllllllll}
\boldsymbol{P}_{i j}^{T} & \boldsymbol{Q}_{i j}^{T} & \boldsymbol{I}_{i j}^{T} & \boldsymbol{P}_{i}^{T} & \boldsymbol{Q}_{i}^{T} & \boldsymbol{I}_{i}^{T} & \boldsymbol{V}_{i}^{T} & \boldsymbol{a}_{l}^{T} & \boldsymbol{\varphi}_{l}^{T}
\end{array}\right]^{T}
$$

gde su $\boldsymbol{P}_{i j}, \boldsymbol{Q}_{i j}$ i $\boldsymbol{I}_{i j}$ vektori tokova aktivnih i reaktivnih snaga i struja po granama, $\boldsymbol{P}_{i}, \boldsymbol{Q}_{i}$ i $\boldsymbol{I}_{i}$ vektori injektiranih aktivnih i reaktivnih snaga i struja u čvorovima, $\boldsymbol{V}_{i}$ vektor modula napona u čvorovima i $\boldsymbol{a}_{l}$ i $\boldsymbol{\varphi}_{l}$ vektori nenominalnih odnosa transformacije klasičnih i faznih regulacionih transformatora, respektivno.

Matrica težinskih faktora ima sledeći oblik:

$$
\boldsymbol{W}=\operatorname{diag}\left\{1 / \sigma_{m}^{2}\right\}
$$


gde je $\sigma_{m}^{2}$ varijansa $m$-tog merenja, koja daje indikaciju o kvalitetu merenja.

Redundansa merenja $R_{d}$ definiše se kao odnos broja raspoloživih merenja $M$ i minimalno potrebnog broja nezavisnih merenja, koji praktično odgovara broju promenljivih stanja sistema $n$, pri čemu je $M>n$ :

$$
R_{d}=\frac{M}{n} \text {. }
$$

\subsection{Observabilnost sistema}

Pod pojmom observabilnosti sistema podrazumeva se mogućnost da se nad razmatranom mrežom izvrši statička estimacija stanja, odnosno da se odredi rešenje vektora promenljivih stanja sa raspoloživim skupom merenja [2].

U skladu sa tim može se izvršiti podela merenja na kritična merenja čijim eliminisanjem sistem postaje neobservabilan, nekritična (redundantna) merenja čijim uklanjanjem sistem ostaje observabilan (povećavaju redundansu merenja, a samim tim i tačnost proračuna) i merenja kritična za jedinstvenost rešenja čijom eliminacijom sistem postaje nejedinstveno observabilan.

\subsection{Kriterijum srednje-kvadratnih odstupanja}

Problem statičke estimacije moguće je formulisati na sledeći način: Pronaći vrednosti promenljivih stanja, pri kojima se ima minimalna suma kvadrata odstupanja između izmerenih i estimiranih vrednosti veličina, pri čemu se svakoj razlici (rezidualu) dodeljuje odgovarajući težinski faktor [3]:

$$
\min _{\boldsymbol{x}}\left\{J(\boldsymbol{x})=\sum_{m=1}^{M} \frac{\left[z_{m}-h_{m}(\boldsymbol{x})\right]^{2}}{\sigma_{m}^{2}}\right\},
$$

gde je $J(\boldsymbol{x})$ ukupna suma kvadrata reziduala merenja (kriterijumska funkcija koja se minimizira), a $h_{m}(\boldsymbol{x})$ oznaka za funkciju $m$-tog merenja.

Sam vektor reziduala se može predstaviti kao:

$$
\boldsymbol{r}=\boldsymbol{z}-h(\boldsymbol{x}),
$$

gde je $\boldsymbol{r}$ vektor reziduala merenja, $\boldsymbol{z}$ vektor merenja i $h(\boldsymbol{x})$ vektor estimiranih vrednosti merenja za dati vektor stanja. Problem (6) je pogodno izraziti u kompaktnoj formi:

$$
\min _{\boldsymbol{x}}\left\{\mathrm{J}(\boldsymbol{x})=\boldsymbol{r}^{T} \boldsymbol{R}^{-1} \boldsymbol{r}=[z-\boldsymbol{h}(\boldsymbol{x})]^{T} \boldsymbol{R}^{-1}[z-\boldsymbol{h}(\boldsymbol{x})]\right\},
$$

gde je $\boldsymbol{R}^{-1}$ već definisana dijagonalna matrica težinskih faktora $\boldsymbol{W}$.

Ako se funkcija vektora merenja $\boldsymbol{h}(\boldsymbol{x})$, iz izraza (2) linearizuje, dobija se sledeća funkcija:

$$
\boldsymbol{z}=\boldsymbol{H} \boldsymbol{x}+\boldsymbol{e},
$$

gde $\boldsymbol{H}$ predstavlja $(M \times n)$ dimenzionu Jakobijan matricu, odnosno osetljivost funkcije vektora merenja $\boldsymbol{h}(\boldsymbol{x})$ na promenu vektora promenljivih stanja $\boldsymbol{x}$ :

$$
\boldsymbol{H}=\left.\frac{\partial \boldsymbol{h}(\boldsymbol{x})}{\partial \boldsymbol{x}}\right|_{\boldsymbol{x}=\hat{\boldsymbol{x}}} .
$$

gde se elementi vektora $\boldsymbol{h}(\boldsymbol{x})$ proračunavaju različito, $\mathrm{u}$ zavisnosti od tipa merenja.

\section{MATEMATIČKI MODEL}

U ovom poglavlju razmatraće se način rešavanja postavljenog problema statičke estimacije stanja. Biće opisane matrice Jakobijana $\boldsymbol{H}$ i pojačanja $\boldsymbol{G}$, uz poseban osvrt na tretman strujnih merenja u proračunu statičke estimacije stanja.

\subsection{Metod normalnih jednačina}

Minimum optimizacione funkcije (8) dobija se izjednačavanjem prvog izvoda funkcije, po vektoru stanja, sa nulom:

$$
\frac{\partial J(\boldsymbol{x})}{\partial \boldsymbol{x}}=\boldsymbol{H}(\boldsymbol{x})^{T} \boldsymbol{R}^{-1}[\boldsymbol{z}-\boldsymbol{h}(\boldsymbol{x})]=0 .
$$

Estimacija vektora promenljivih stanja se dobija iterativnim rešavanjem prethodnog sistema nelinearnih jednačina, koji se u svakoj iteraciji linearizuje, čime se dobija sledeći sistem linearnih jednačina [4]:

$$
\begin{gathered}
\boldsymbol{G}\left(\boldsymbol{x}^{(k)}\right) \boldsymbol{\Delta} \boldsymbol{x}^{(k)}=\boldsymbol{H}\left(\boldsymbol{x}^{(k)}\right) \boldsymbol{R}^{-1} \boldsymbol{\Delta} \boldsymbol{z}^{(k)} ; k=0,1,2 \ldots \\
\boldsymbol{x}^{(k+1)}=\boldsymbol{x}^{(k)}+\Delta \boldsymbol{x}^{(k)}
\end{gathered}
$$

gde je $\boldsymbol{G}\left(\boldsymbol{x}^{(k)}\right)=\boldsymbol{H}\left(\boldsymbol{x}^{(k)}\right)^{T} \boldsymbol{R}^{-1} \boldsymbol{H}\left(\boldsymbol{x}^{(k)}\right)$ matrica pojačanja u $\quad k$-toj iteraciji, $\boldsymbol{\Delta} \boldsymbol{z}^{(k)}=\boldsymbol{z}-h\left(\boldsymbol{x}^{(k)}\right)$ priraštaj vektora merenja u $k$-toj iteraciji, $\boldsymbol{H}\left(\boldsymbol{x}^{(k)}\right)$ matrica Jakobijana u $k$ toj iteraciji i $\boldsymbol{\Delta} \boldsymbol{x}^{(k)}$ korekcija vektora stanja u $k$-toj iteraciji.

Iterativni postupak se završava kada je ispunjen sledeći uslov:

$$
\max \{\Delta \boldsymbol{x}\} \leq \xi,
$$

gde je $\xi$ unapred zadati kriterijum konvergencije.

\subsection{Formiranje Jakobijan matrice}

Dimenzije i struktura matrice Jakobijana zavise od vektora raspoloživih merenja i vektora promenljivih stanja [2]:

$$
\boldsymbol{H}=\left[\begin{array}{lllllll}
\frac{\partial \boldsymbol{P}_{i j}}{\partial \boldsymbol{V}} & \frac{\partial \boldsymbol{Q}_{i j}}{\partial \boldsymbol{V}} & \frac{\partial \boldsymbol{I}_{i j}}{\partial \boldsymbol{V}} & \frac{\partial \boldsymbol{P}_{i}}{\partial \boldsymbol{V}} & \frac{\partial \boldsymbol{Q}_{i}}{\partial \boldsymbol{V}} & \frac{\partial \boldsymbol{I}_{i}}{\partial \boldsymbol{V}} & \frac{\partial \boldsymbol{V}_{i}}{\partial \boldsymbol{V}} \\
\frac{\partial \boldsymbol{P}_{i j}}{\partial \boldsymbol{\theta}} & \frac{\partial \boldsymbol{Q}_{i j}}{\partial \boldsymbol{\theta}} & \frac{\partial \boldsymbol{I}_{i j}}{\partial \boldsymbol{V}} & \frac{\partial \boldsymbol{P}_{i}}{\partial \boldsymbol{\theta}} & \frac{\partial \boldsymbol{Q}_{i}}{\partial \boldsymbol{\theta}} & \frac{\partial \boldsymbol{I}_{i}}{\partial \boldsymbol{\theta}} & \frac{\partial \boldsymbol{V}_{i}}{\partial \boldsymbol{\theta}}
\end{array}\right]^{T}
$$

Elementi matrice Jakobijana koji odgovaraju strujnim merenjima, definišu se na sledeći način:

$$
\begin{gathered}
\frac{\partial I_{i j}}{\partial V_{i}}=\frac{g_{i j}^{2}+b_{i j}^{2}}{I_{i j}}\left(V_{i}-V_{j} \cos \theta_{i j}\right), \\
\frac{\partial I_{i j}}{\partial V_{j}}=\frac{g_{i j}^{2}+b_{i j}^{2}}{I_{i j}}\left(V_{j}-V_{i} \cos \theta_{i j}\right), \\
\frac{\partial I_{i j}}{\partial \theta_{i}}=\frac{g_{i j}^{2}+b_{i j}^{2}}{I_{i j}} V_{i} V_{j} \sin \theta_{i j}, \\
\frac{\partial I_{i j}}{\partial \theta_{j}}=-\frac{g_{i j}^{2}+b_{i j}^{2}}{I_{i j}} V_{i} V_{j} \sin \theta_{i j} .
\end{gathered}
$$


Ukoliko u sistemu postoje merenja injektiranih struja u čvorove, ona mogu biti iskorišćena u proračunu statičke estimacije stanja. Ovakva merenja uključuju se u proračun na veoma sličan način kao i merenja struja u granama i sa sobom nose iste probleme vezane za korišćenje strujnih merenja u statičkom estimatoru stanja [2].

\section{VERIFIKACIJA MATEMATIČKOG MODELA}

Verifikacija matematičkog modela za proračun statičke estimacije stanja izvršena je na 2 test sistema. Prvi test sistem je formiran od 3, a drugi od 14 čvorova [2].

\subsection{Test mreža sa 3 čvora - sa strujnim merenjima}

Test sistem sa 3 čvora prikazan je na slici 1 .

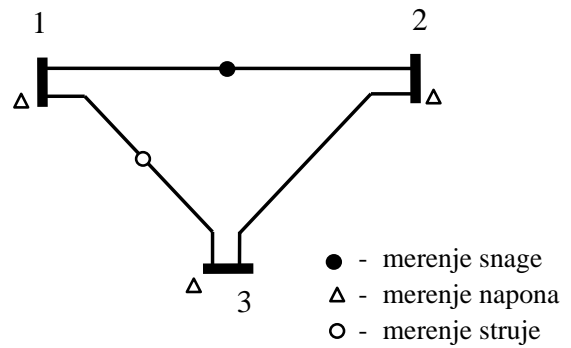

Slika 1 - Test mreža sa 3 čvora

Parametri koji opisuju topologiju mreže dati su u relativnim jedinicama i prikazani u tabeli 1 .

Tabela 1 - Podaci o topologiji sistema sa 3 čvora [2]

\begin{tabular}{|c|c|c|c|c|c|c|}
\hline Čvor 1 & Čvor 2 & Tip & $r[\mathrm{r} . \mathrm{j}]$. & $x[\mathrm{r} . \mathrm{j}]$. & $b[\mathrm{r} . \mathrm{j}]$. & $g[\mathrm{r} . \mathrm{j}]$. \\
\hline 1 & 2 & $\operatorname{vod}$ & 0,01 & 0,03 & 0 & 0 \\
\hline 1 & 3 & $\operatorname{vod}$ & 0,02 & 0,05 & 0 & 0 \\
\hline 2 & 3 & $\operatorname{vod}$ & 0,03 & 0,08 & 0 & 0 \\
\hline
\end{tabular}

Vrednosti i raspored merenja korišćenih u proračunu prikazani su u tabeli 2 .

Tabela 2 - Podaci o merenjima sistema sa 3 čvora [2]

\begin{tabular}{|c|c|c|c|}
\hline Čvor 1 & Čvor 2 & Tip & Vrednost merenja [r.j.] \\
\hline 2 & 2 & $P_{2}$ & $-0,501$ \\
\hline 2 & 2 & $Q_{2}$ & $-0,286$ \\
\hline 1 & 2 & $P_{12}$ & 0,888 \\
\hline 1 & 3 & $P_{13}$ & 1,173 \\
\hline 1 & 2 & $Q_{12}$ & 0,568 \\
\hline 1 & 3 & $Q_{13}$ & 0,663 \\
\hline 1 & 1 & $V_{1}$ & 1,006 \\
\hline 2 & 2 & $V_{2}$ & 0,968 \\
\hline
\end{tabular}

Ukoliko se za inicijalne vrednosti vektora stanja $\boldsymbol{x}$ usvoje nominalne vrednosti, elementi matrice Jakobijana koji odgovaraju strujnim merenjima jednaki su nuli. Iz ove činjenice može se zaključiti da se strujna merenja ne mogu iskoristiti u situaciji kada za inicijalne vrednosti elemenata vektora promenljivih stanja usvoje jedinične vrednosti napona koji su pri tom u fazi.

Kako bi se rešio ovaj problem, za inicijalne vrednosti vektora $\boldsymbol{x}$ se mogu usvojiti vrednosti koje malo odstupaju od nominalnih:

$$
\boldsymbol{x}=\left[\begin{array}{llllll}
0 & 5,70 & 8,60 & 1 & 0,95 & 1,05
\end{array}\right]^{T} .
$$

Za ovako usvojenu inicijalnu vrednost vektora stanja i usvojeni kriterijum konvergencije $\xi=0,0001$, proračun konvergira u 6 iteracija. U tabeli 3 prikazane su vrednosti funkcije cilja (sume otežanih kvadrata reziduala merenja), kao i maksimalnog odstupanja vektora promenljivih stanja, kroz svih 6 iteracija.

Tabela 3 - Funkcija cilja i maksimalna odstupanja vektora $\boldsymbol{x}$ po iteracijama

\begin{tabular}{|c|r|c|}
\hline Iteracija & \multicolumn{1}{|c|}{$J(\boldsymbol{x})$} & $\max \{\boldsymbol{\Delta x}\}$ \\
\hline 1 & 624060,1 & $1,25 \cdot 10^{-1}$ \\
\hline 2 & 163442,3 & $5,36 \cdot 10^{-2}$ \\
\hline 3 & 7028,8 & $2,01 \cdot 10^{-2}$ \\
\hline 4 & 140,2 & $3,87 \cdot 10^{-3}$ \\
\hline 5 & 4,9 & $1,55 \cdot 10^{-4}$ \\
\hline 6 & 4,7 & $2,48 \cdot 10^{-7}$ \\
\hline
\end{tabular}

Proračunati vektor stanja ima sledeće vrednosti:

$$
\boldsymbol{x}=\left[\begin{array}{llllll}
0 & -1,234 & 2,766 & 1,000 & 0,974 & 0,944
\end{array}\right]^{T} .
$$

Drugi problem korišćenja strujnih merenja u proračunu statičke estimacije stanja, uočava se ukoliko se za inicijalnu vrednost vektora $\boldsymbol{x}$ usvoji nešto drugačija vrednost:

$$
\boldsymbol{x}=\left[\begin{array}{llllll}
0 & -5,70 & -8,60 & 1 & 0,95 & 1,05
\end{array}\right]^{T} .
$$

$\mathrm{U}$ ovoj situaciji proračun će ponovo konvergirati u 6 iteracija, sa sličnim vrednostima $J(\boldsymbol{x})$ i $\max \{\boldsymbol{\Delta} \boldsymbol{x}\}$, ali ovaj put ka drugom rešenju:

$$
\boldsymbol{x}=\left[\begin{array}{llllll}
0 & -1,234 & -2,766 & 1,000 & 0,974 & 0,944
\end{array}\right]^{T} .
$$

Ovim je potvrđeno da za dati skup raspoloživih merenja, postoje 2 rešenja statičkog estimatora stanja, odnosno dokazano je da u prisustvu strujnih merenja, sistem može biti nejedinstveno observabilan.

\subsection{Test mreža sa 14 čvorova - sa strujnim merenjima}

Test sistem sa 14 čvorova i raspored merenja, prikazani su na slici 2. Može se uočiti da u sistemu postoje merenja modula napona i struje potrošnje na svim sabirnicama, uz još 8 merenja modula struja u granama.

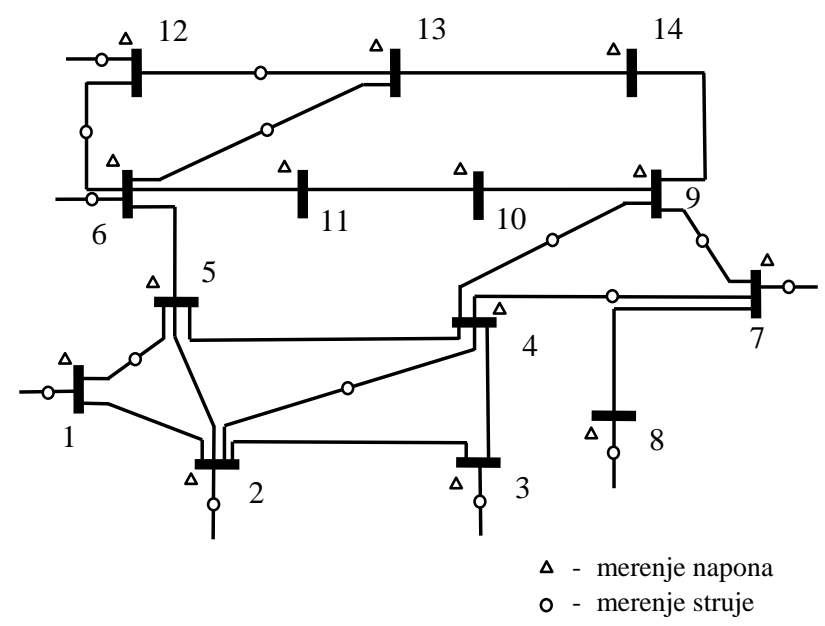

Slika 2 - Test mreža sa 14 čvorova

U tabeli 5 date su vrednosti korišćenih merenja modula struja po granama. 
Tabela 5 - Vrednosti merenja modula struja po granama

\begin{tabular}{|c|c|r|}
\hline Čvor 1 & Čvor 2 & $I_{i j}[\mathrm{r} . j]$. \\
\hline 1 & 5 & 0,228 \\
\hline 2 & 4 & 0,150 \\
\hline 4 & 7 & 0,301 \\
\hline 4 & 9 & 0,053 \\
\hline 6 & 12 & 0,016 \\
\hline 6 & 13 & 0,045 \\
\hline 7 & 9 & 0,338 \\
\hline 12 & 13 & 0,032 \\
\hline
\end{tabular}

Izmereni moduli struje potrošnje imaju sledeće vrednosti: $I_{1}=0,956, I_{2}=0,305, I_{3}=0,999, I_{4}=0,460, I_{5}=0,216$, $I_{6}=0,126, I_{7}=0, I_{8}=0,446, I_{9}=0,322, I_{10}=0,104, I_{11}=$ $0,294, I_{12}=0,061, I_{13}=0,155, I_{14}=0,154$.

$\mathrm{U}$ ovom primeru, usled velikog broja i dobrog rasporeda merenja, proračun konvergira u samo 4 iteracije.

Iz ovoga se može zaključiti da postojanje merenja aktivnih i reaktivnih snage ne predstavlja neophodan preduslov za postojanje jedinstveno observabilnog sistema.

\subsection{Analiza osetljivosti sistema sa 14 čvorova (bez merenja snage)}

$\mathrm{Na}$ test sistemu iz prethodnog primera izvršena je analiza osetljivosti estimiranih napona u čvorovima 1 i 5 , na promenu izmerene vrednosti struje u grani 1-5, slika 3 .

Za relativnu grešku merenja biće usvojena vrednost koja iznosi $\pm 5 \%$, što znači da će se vrednost struje $I_{15}$, u ovom primeru kretati u opsegu od $I_{15 \min }=0,217$ [r.j.], do $I_{15 \max }$ $=0,239$ [r.j.]. Proračun vrednosti napona čvorova 1 i 5 , sproveden je za vrednosti merenja struje u grani $1-5 \mathrm{iz}$ opsega od $I_{15 \min }$ do $I_{15 \max }$, sa korakom od 0,00114 (20 tačaka).

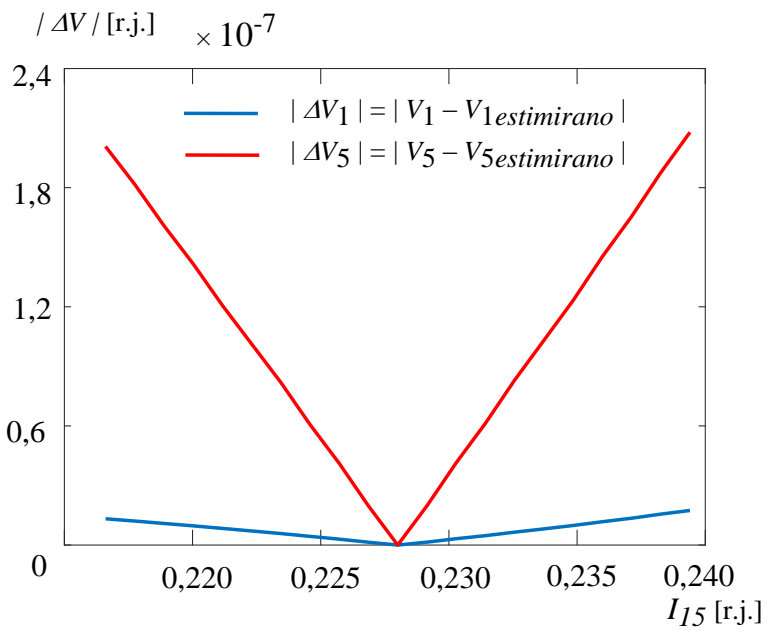

Slika 3 - Analiza osetljivosti na test sistemu sa 14 čvorova (bez merenja snage)

Sa slike 3 se može primetiti da je osetljivost estimiranih vrednosti napona na grešku merenja modula struje zanemarljivo mala (reda veličine $\sim 10^{-7}$ ).

Situacija bi bila drastično drugačija kada bi se razmatrao uticaj greške merenja modula napona na estimirane vrednosti [4].

\section{ZAKLJUČAK}

U ovom radu izvršena su brojna zanemarenja, ali nije se izgubilo na opštosti samog proračuna. Osnovni zaključak vezan za statičku estimaciju stanja u prenosnim mrežama, jeste da je osnova za validne i upotrebljive rezultate, raspolaganje sa kvalitetnim skupom, dobro raspoređenih $\mathrm{i}$ redundantnih merenja, odnosno pravilno tretiranje raspoloživih merenja.

Objašnjen je tretman merenja različitog tipa, kao i metod minimuma sume otežanih kvadrata reziduala za rešavanje sistema nelinearnih, algebarskih i simultanih jednačina.

Ovakav pristup za rešavanje problema statičke estimacije stanja na realnim EES-ima ima i svoje nedostatke. Neki od tih nedostataka prikazani su kroz analizu uticaja strujnih merenja na proračun statičke estimacije. Zaključeno je da mnoga ranije ustanovljena pravila (kao što je činjenica da Jakobijan matrica punog ranga implicira jedinstveno rešenje statičkog estimatora stanja), ne važe u slučaju prisustva strujnih merenja.

Velika dimenzionalnost sistema zahteva primenu tehnike retkih matrica za memorisanje matrice admitansi. Zbog toga je veoma bitno koristiti što efikasnije programske alate za faktorizaciju, množenje matrica i rešavanje sistema linearnih jednačina, sve to u cilju što bržeg $i$ efikasnijeg proračuna koji predstavlja osnovu za sve druge energetske funkcije.

Takođe, u realnim EES-ima, postoje velike varijacije $\mathrm{u}$ dužinama vodova, što utiče na numeričku stabilnost proračuna, a svakako i na osetljivost estimiranih vrednosti napona čvorova na izmerene vrednosti u granama kojima su oni povezani. Upravo ova razmatranja predstavljala bi logičan nastavak ovog rada.

\section{LITERATURA}

1. A.T.Sarić, M.S.Ćalović: Statička estimacija stanja u elektroenergetskim sistema, Tehnički fakultet Čačak, Kraljevo, 2008.

2. A.Abur: Power System State Estimation, Theory and Implementation, Texas A\&M University, College Station, Texas, U.S.A, 2004.

3. A.Monticelli: State estimation in electric power systems, a generalized approach, University of Campinas, Norwell, Massachusetts, U.S.A, 1999.

4. G.Švenda: Specijalizovani softveri u elektroenergetici, skripta sa predavanja iz istoimenog predmeta na master studijama, Fakultet Tehničkih Nauka, Novi Sad, 2016.

\section{Kratka biografija:}

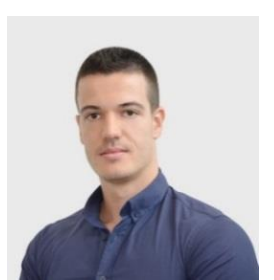

Miroslav Pavlović rođen je $\mathrm{u}$ Novom Sadu 1993. godine. Diplomski rad na Fakultetu tehničkih nauka u Novom Sadu odbranio je 2016. godine u oblasti Elektrotehnika i računarstvo, smer Elektroenergetski sistemi. Iste godine upisuje master studije na istom smeru. 